\title{
Cervical hematoma spontaneously caused by a broken parathyroid cyst
}

\author{
Hematom cervical spontan cauzat de un chist paratiroidian rupt \\ Adina GHEMIGIAN ${ }^{1}$, Claudiu JUPEA ${ }^{1}$, Corina NEAMTU ${ }^{1}$, Diana PAUN ${ }^{1}$, Adrian TULIN² \\ ${ }^{1}$ Institutul Naţional de Endocrinologie „C.I. Parhon“, Bucureşti, România \\ 2Spitalul Clinic de Urgenţă „Prof. Dr.Agrippa Ionescu“, Bucureşti, România
}

\begin{abstract}
Parathyroid cysts are relatively rare lesions of the neck, usually millimetric in size and without clinical consequences. By contrast, macrocystic forms require additional investigations and often treatment. A cervical hematoma caused by a ruptured parathyroid cyst is extremely rare and usually occurs due to cystic degeneration of an adenoma. We present the case of a male patient with spontaneous cervical hematoma caused by a ruptured parathyroid cyst with rapidly evolving and severe compressive manifestations occurring after an episode of upper respiratory infection. Differential diagnosis is difficult, especially under emergency condi-tions, and surgical treatment should not be delayed.
\end{abstract}

Keywords: cervical cyst, parathyroid adenoma, hematoma, hyperparathyroidism

\section{REZUMAT}

Chisturile paratiroidiene sunt formațiuni cervicale relativ rare, cel mai adesea milimetrice şi lipsite de consecințe clinice. Prin contrast, formele macrochistice necesită investigații suplimentare şi, în multe situații, tratament. Hematomul cervical cauzat de ruptura unui chist paratiroidian este extrem de rar şi apare de obicei pe fondul degenerării chistice a unui adenom. Prezentăm cazul unui bărbat cu un hematom cervical spontan cauzat de un chist paratiroidian rupt, rapid evolutiv, cu manifestări compresive severe, apărut după un episod de infecție respiratorie superioară. Diagnosticul diferențial este dificil, în special în condiții de urgență, iar tratamentul chirugical nu ar trebui întârziat.

Cuvinte cheie: chist cervical, adenom paratiroidian, hematom, hiperparatiroidism

\section{INTRODUCERE}

Diagnosticul diferenţial al maselor chistice de la nivelul gâtului include chisturile tiroidiene, timice, de duct tireoglos, branhiale, bronhogene, limfangioamele și chisturile paratiroidiene (1). Acestea din urmă reprezintă una dintre cauzele mai puţin frecvente, fiind adesea ignorate în etapele iniţiale de stabilire a diagosticului unei mase cervicale clinic evidente.
Chisturile de glandă paratiroidă sunt formaţiuni cervicale sau mediastinale, în funcţie de localizarea glandei afectate, și au fost descrise iniţial în 1880 (2). Formele infracentimetrice sunt mai frecvent găsite la vârste înaintate, adesea descrise la autopsie, fără consecinţe clinice (3). Formaţiunile de peste $1 \mathrm{~cm}$ pot fi clinic evidente și necesită investigaţii suplimentare. Marea majoritate (85\%) sunt situate la nivel cervical, au 
dimensiuni medii de 3-5 cm, dar pot depăși și 10 cm (1) și, așa cum vom prezenta în continuare, pot determina simptome compresive.

Cele mai multe chisturi paratiroidiene sunt nefuncționale (4), fomele care determină hiperparatiroidism fiind explicate de obicei prin degenerarea chistică a unui adenom sau carcinom paratiroidian și nu de o leziune chistică primară (5).

Stabilirea diagnosticului de chist paratiroidan pe baze clinice sau imagistice este dificilă, principalul diagnostic diferențial fiind o masă tiroidiană $(6,7)$. Aspirația chistului și măsurarea nivelul de PTH din aspirat, cu găsirea unor valori de sute sau $\mathrm{mii} \mathrm{pg} / \mathrm{ml}$ (chiar și în cazul formelor nefuncționale), confirmă diagnosticul (8).

Tratamentul formelor simptomatice sau funcționale este chirurgical. Uneori, aspirația poate fi singurul tratament necesar.

\section{PREZENTARE DE CAZ}

Pacient în vârstă de 51 ani, cu stare anterioară bună, se prezintă la începutul lunii decembrie 2016 la medicul de familie cu simptome de infecție respiratorie superioară: tuse, durere în gât și febră. Primește tratament antibiotic și simptomatic, cu ameliorarea manifestărilor inițiale, dar dezvoltă în urmatoarele 7 zile o tumefacție cervicală antero-laterală stângă, cu creștere semnificativă în ultimele 48 de ore, disfagie la solide și dispnee de efort. Se prezintă la camera de gardă de la secția Chirugie generală și este internat pentru evaluare, supraveghere și stabilirea conduitei terapeutice.

Istoricul familial este nesemnificativ, iar din istoricul personal reținem doar o dislipidemie. Fără antecedente de afecțiuni tiroidiene.

Clinic, pacient cu stare generală bună, obezitate gradul I, afebril, fără modificări tegumentare și echilibrat cardiorespirator la prezentare. Inspecția regiunii cervicale decelează o tumefacție anterolaterală ce modifică conturul gâtului de partea stangă. La palpare, loja tiroidiană stângă este mult mărită de volum, discret sensibilă la palpare, minim mobilă la deglutiție.

Testele de laborator efectuate în urgență indică absența unui sindrom inflamator semnificativ și atestă eutiroidia. De asemenea, calciul seric este în limite normale.

Se inițiază tratament empiric antibiotic și antiinflamator.

Pe parcursul orelor următoare tumefacția cervicală se mărește, devine evident bilaterală și apar echimoze la nivel cervical antero-lateral stâng (Fig. 1). De asemenea, se accentuează manifestările compresive, dispneea și disfagia.

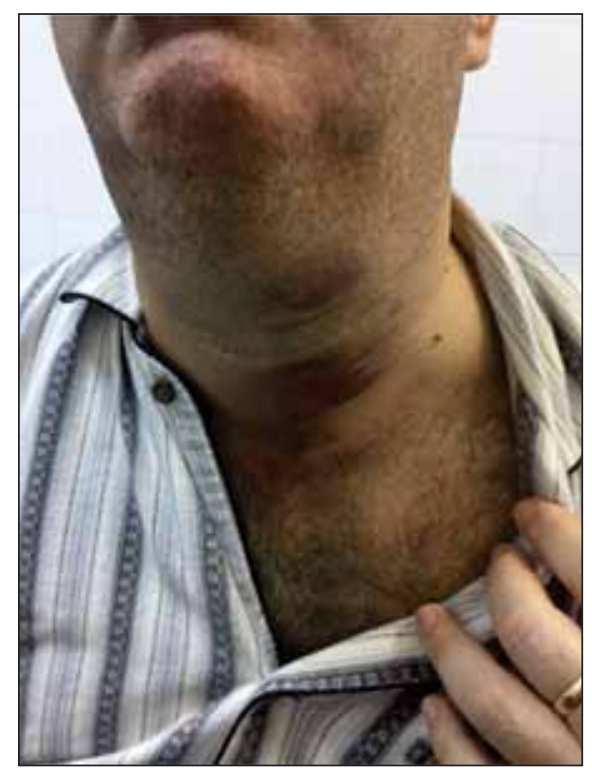

\section{FIGURA 1}

Pacientul este trimis în consult endocrinologic, unde se confirmă și clinic statusul eutiroidian și se efectuează ecografia de tiroidă. Aceasta descrie un lob stâng mult mărit de volum, hipoecogen, greu delimitabil față de structurile din jur, cu mai multe arii chistice și componentă solidă cu diferite grade de ecogenitate. În polul inferior se delimitează ceva mai clar o formațiune de $4 / 3.7 \mathrm{~cm}$, ușor vascularizată periferic. Polul inferior al lobului stâng nu s-a putut vizualiza complet. Lobul drept este clar vizibil, cu volum normal și ecostructură hipoecogenă și neomogenă. Laterocervical se evidențiază doar adenopatii cu aspect inflamator. Pe baza istoricului, examinării și ecografiei se ridică suspiciunea de tiroidită acută, cu manifestări locale (semne de inflamație cervicală) și generale atenuate de tratamentul antibiotic și antiinflamator. Se exclude o formațiune tumorală având în vedere evoluția extrem de rapidă și absența elementelor ecografice sugestive (adenopatii suspecte, calcificări). Se recomandă continuarea tratamentului antibiotic și antiinflamator, supraveghere și intervenție chirurgicală urgentă dacă nu apar semne de ameliorare.

Se efectueaza și un examen CT care ridică suspiciunea de tromboză de venă jugulară, pentru care se inițiază tratament anticoagulant parenteral. În ciuda tratamentului combinat, pe parcursul următoarelor 12 ore fenomenele compresive se accentuează, pacientul dezvoltând insuficiență respiratorie.

Se intervine chirurgical sub AGIOT în urgență prin incizie cervicală anterioară tip KOCHER, iar 
intraoperator se identifică hematom local extins cu punct de plecare aparent de la nivelul polului inferior al lobului stâng tiroidian, cu infiltrarea mușchiului sternocleidomastoidian stâng, sternohiodian stâng și întreaga lojă tiroidiană stângă cu efect compresiv pe trahee (deplasare către dreapta) și pe mănunchiul vasculonervos stâng al gâtului (nerv vag, vena jugulară internă, artera carotidă comună), fără a se identifica o sursă activă de sângerare. Se practică tiroidectomie totală și evacuarea hematomului.

Evoluţia postoperatorie a fost favorabilă cu remisia completă a simptomatolgiei compresive dar și dispariţia echimozelor cervicale anterioare. Pacientul a fost externat în ziua 4 postoperator, sub tratament substitutiv cu levotiroxină și recomandare de reevaluare endocrinologică ulterioară.

Examenul histopatologic stabilește diagnosticul de chist paratiroidian rupt, cu arii de hemoragie, necroză și infiltrat inflamator polimorf. Glanda tiroidă prezintă doar modificări de tiroidită cronică.

\section{DISCUŢII}

Chisturile paratiroidiene sunt formaţiuni cervicale relativ rare, cel mai adesea nefuncţionale și asimptomatice. Din datele raportate in literatură, hematoamele cervicale spontane cu origi- ne paratiroidiană sunt extrem de rare și apar în cele mai multe cazuri ca urmare a unei degenerări hemoragice într-un adenom (9). De asemenea, asociază tablou biochimic de hiperparatiroidism primar (hipercalcemie și nivel crescut al PTH). În cazul prezentat de noi, examenul histopatologic nu descrie prezenţa unui adenom paratiroidian, aspect confirmat și de nivelul preoperator normal al calcemiei. Din punct de vedere clinic, debutul a fost legat de o infecţie de căi respiratorii, iar evoluţia a fost zgomotoasă și rapidă, ceea ce a impus tratamentul chirurgical urgent. Diagnosticul diferenţial la un pacient fără istoric de formaţiuni tiroidiene sau paratiroidiene este dificil, în special când hematomul este de dimensiuni mari și fuzează în spaţiile cervicale.

Deși extrem de rar, hematomul cauzat de ruptura unui chist paratiroidian trebuie luat în considerare la un pacient care se prezintă cu o formaţiune compresivă, rapid progresivă în interval de zile sau ore, eventual asociată cu echimoze spontane la nivelul gâtului. Alte cauze, toate rare, de hematom cervical spontan sunt: disecţia unui anevrism (în special de arteră tiroidiană inferioară), sîngererea intratumorală, diatezele hemoragice (10). Absenţa sindromului inflamator și a semnelor și simptomelor de infecţie reprezintă argumente suplimentare pentru acest diagnostic.

Conflict of interest: none declared Financial support: none declared

\section{BIBLIOGRAFIE}

1. Fortson J.K., Patel V.G., Henderson V.J. Parathyroid cysts: a case report and review of the literature. Laryngoscope 2001; 111:1726.

2. Ferrara B.E., Hazell S., Parker T.H., Rutland E.D. Parathyroid cyst. South Med J 1985; 78:528.

3. Ippolito G., Palazzo F.F., Sebag F. et al. A single-institution 25-year review of true parathyroid cysts. Langenbecks Arch Surg 2006; 391:13

4. McCoy K.L., Yim J.H., Zuckerbraun B.S. et al. Cystic parathyroid lesions: functional and nonfunctional parathyroid cysts. Arch Surg 2009; 144:52.
5. Wani S., Hao Z. Atypical cystic adenoma of the parathyroid gland: case report and review of literature. Endocr Pract 2005; 11:389.

6. Cao H., Lai C.K., Head C.S., Sercarz J.A. Cystic parathyroid presenting as an apparent thyroid goiter. Eur Arch Otorhinolaryngol 2008; 265: 1285-8.

7. Ujiki M.B., Nayar R., Sturgeon C., Angelos P. Parathyroid cyst:often mistaken for a thyroid cyst. World J Surg 2007; 31:60-64.

8. Mevio E., Gorini E., Sbrocca M., Artesi L., Mulace M., Lecce S. Parathyroid cysts: description of two cases and review of the literature. Acta Otorhinolaryngol Ital 2004; 24:161-4.

9. Jordan F.T., Harness J.K., Thompson N.W. Spontaneous cervical hematoma: a rare manifestation of parathyroid adenoma. Surgery. 1981; 89: 697-700.

10. Markus Stenner, Victor Helmstaedter, Elmar Spuentrup, Gero Quante, Karl-Bernd Huettenbrink, Cervical hemorrhage due to spontaneous rupture of the superior thyroid artery: Case report and review of the literature, Head \& Neck, 2010, $32,9$. 